\title{
Prevalence of Enhancer of Zeste Homolog 2 in Patients with Resected Small Cell Lung Cancer
}

\author{
GOUJI TOYOKAWA ${ }^{1}$, KAZUKI TAKADA $^{1}$, TETSUZO TAGAWA ${ }^{1}$, FUMIHIKO KINOSHITA ${ }^{1}$, YUKA KOZUMA ${ }^{1}$, \\ TAICHI MATSUBARA ${ }^{1}$, NAOKI HARATAKE ${ }^{1}$, SHINKICHI TAKAMORI ${ }^{1}$, TAKAKI AKAMINE $^{1}$, \\ FUMIHIKO HIRAI ${ }^{1}$, YUICHI YAMADA ${ }^{2}$, RYUJI HAMAMOTO ${ }^{3}$, YOSHINAO ODA ${ }^{2}$ and YOSHIHIKO MAEHARA ${ }^{1}$ \\ ${ }^{1}$ Department of Surgery and Science, Graduate School of Medical Sciences, Kyushu University, Fukuoka, Japan; \\ ${ }^{2}$ Department of Anatomic Pathology, Graduate School of Medical Sciences, Kyushu University, Fukuoka, Japan; \\ ${ }^{3}$ Division of Molecular Modification and Cancer Biology, National Cancer Center, Tokyo, Japan
}

\begin{abstract}
Background/Aim: Enhancer of zeste homolog 2 (EZH2) is a histone methyltransferase that is deeply involved in cancer pathogenesis. Although clinicopathological significance of EZH2 in non-small cell lung cancer has been gradually elucidated, such significance in small cell lung cancer (SCLC) has yet to be fully investigated. Patients and Methods: Forty patients with resected SCLC were analyzed for EZH2. EZH2 expression was evaluated using the Allred score $(0-8)$ and was classified into negative (0-6) and positive ( 7 and 8). We evaluated the association between EZH2 and the clinicopathological characteristics and postoperative survivals. Results: Among 40 patients, 15 (37.5\%) and 25 (62.5\%) were classified as being negative and positive for EZH2, respectively. Fisher's exact test demonstrated no significant associations between the positivity for EZH2 and clinicopathological characteristics. No significant differences were observed in recurrence-free and overall survivals between EZH2-negative/low and EZH2-high patients. Conclusion: EZH2 was frequently observed in patients with resected SCLC, but no significant associations were found between its expression and the clinicopathological characteristics and postoperative survivals.
\end{abstract}

Small cell lung cancer (SCLC) is an extremely devastating neoplasm and its prognosis remains very poor. Although SCLC is known to respond well to radiotherapy and chemotherapy, relapse after such treatment is very frequently encountered (1). In addition to radiotherapy and

Correspondence to: Gouji Toyokawa, Department of Surgery and Science, Graduate School of Medical Sciences, Kyushu University, 3-1-1 Maidashi, Higashi-ku, Fukuoka 812-8582, Japan. Tel: +81 926425466, Fax: +81 926425482, e-mail: gouji104kawa@gmail.com

Key Words: Small cell lung cancer, enhancer of zeste homolog 2, surgery. chemotherapy, clinical benefit of surgical resection for patients with SCLC has been also reported (2-5); however, most patients inevitably encounter recurrence and eventual death and therefore, novel effective treatments should be developed and applied for patients with SCLC. With regard to immunotherapy for SCLC, a recent phase $1 / 2$ trial demonstrated the durable responses of nivolumab, a programmed death-1 antibody, alone and nivolumab combined with ipilimumab, a cytotoxic T-lymphocyte antigen-4 (CTLA-4) antibody in recurrent SCLC (6): objective response rates of nivolumab monotherapy and nivolumab plus ipilimumab were $10 \%$ and $19-33 \%$, respectively. Despite the possible efficacy of immunotherapy for SCLC, primary and acquired resistances inevitably occur and further promising therapeutic targets should be therefore investigated in the treatment of SCLC.

Histone methyltransferases are deeply involved in the transcriptional regulation of various genes via the methylation of histone tails and their associations with human cancer have been gradually elucidated (7). Among the histone methyltransferases, enhancer of zeste homolog 2 (EZH2) has a catalytic SET domain as a conserved domain among species and methylated lysine residue 27 on histone H3 (H3K27), which leads to transcriptional repression. EZH2 was shown to be associated with murine embryonic development through the regulation of H3K27-methylation-related transcription. Regarding its involvement in human cancer, a line of reports has demonstrated that EZH2 was overexpressed in various types of human cancer, including lung cancer (8-11). Furthermore, somatic mutations within two residues in the catalytic SET domain of the EZH2 gene (Y641 and A677) were identified to increase $\mathrm{H} 3 \mathrm{~K} 27$ tri-methylation and to alter the substrate specificity of the mutated $E Z H 2$ in diffuse large B-cell lymphoma and follicular lymphoma (12). Such mutations were not found in our analysis focusing on patients with SCLC (13); however, EZH2 was reported to promote E2F-driven tumorigenesis of SCLC via the modulation of 
apoptosis and cell-cycle regulation (14). However, the clinicopathological significance of EZH2 protein expression in the resected SCLC remains to be clarified.

In the current study, the relationship between EZH2 expression and the clinicopathological characteristics of patients with resected SCLC and its prognostic influence on their postoperative survival were evaluated.

\section{Patients and Methods}

Study patients. Among 62 patients with SCLC who underwent surgery at the Department of Surgery and Science, Graduate School of Medical Sciences, Kyushu University between April 1974 and August 2015, 40 patients, whose resected specimens could be analyzed of EZH2, were included in this translational study. Pathological staging was performed using the 7th edition of the TNM Classification of Malignant Tumors. In addition to the pathological stage, the patients' age, gender, performance status, smoking history, pathological tumor and pathological lymph nodal factors, pleural invasion (pl), lymphatic invasion (ly), vascular invasion (v) and surgical procedure were examined. The present study was approved by our institutional review board (the Number of the Ethic Approval: 28-380).

Immunohistochemical analyses. Immunohistochemistry was performed as described previously $(15,16)$. Sections were cut $(4 \mu \mathrm{m}$ thickness), dewaxed with xylene, and rehydrated through a graded series of ethanol. After inhibition of endogenous peroxidase activity for $30 \mathrm{~min}$ with $3 \% \mathrm{H}_{2} \mathrm{O}_{2}$ in methanol, the sections were pretreated with Target Retrieval Solution (Dako, Glostrup, Denmark) in a decloaking chamber at $110^{\circ} \mathrm{C}$ for $15 \mathrm{~min}$ and then incubated with monoclonal antibodies at $4^{\circ} \mathrm{C}$ overnight. Immune complexes were detected with a DAKO EnVision Detection System (Dako). The sections were finally reacted in 3,3'-diaminobenzidine, counterstained with hematoxylin, and mounted. The primary antibody for EZH2 was an anti-human EZH2 mouse monoclonal antibody (clone 6A10, dilution 1:100; Leica Biosystems, Newcastle, UK). Carcinoma cells showing nuclear staining for EZH2 were considered to be positive cells. Allred scores were applied to evaluate EZH2 expression (17). The primary antibody for programmed death-ligand 1 (PD-L1) was an anti-human PD-L1 rabbit monoclonal antibody (clone SP142, dilution 1:100; Spring Bioscience, Ventana, Tucson, AZ, USA). Carcinoma cells showing membranous staining for PD-L1 were evaluated as positive cells. The proportion of PD-L1-positive cells was estimated as the percentage of total carcinoma cells. The cut-off values were set at $5 \%$ as described previously (18). Human tonsils and placentas were used as positive controls for EZH2 and PD-L1, respectively. The evaluations were performed independently by three investigators (G.T., K.T. and Y.Y.). If the independent assessments did not agree, the slides were reviewed together to achieve consensus. The consensus judgments were adopted as the final results.

Spread through air spaces (STAS). STAS was defined as tumor cells within air spaces in the lung parenchyma beyond the edge of the main tumor $(19,20)$. In addition, STAS was also classified into the following three categories: "no STAS" for cases without definite STAS, "low STAS" for cases with 1 to 4 single cells or clusters of STAS, and "high STAS" for cases with five or more single cells or clusters of STAS (21). All tumors were evaluated at a magnification of $\times 200$ using an optical microscope (BX40; Olympus, Tokyo, Japan).
Table I. Patient characteristics.

\begin{tabular}{|c|c|}
\hline Factors & $\mathrm{N}$ \\
\hline \multicolumn{2}{|l|}{ Age (years) } \\
\hline$<70$ & 21 \\
\hline$\geq 70$ & 19 \\
\hline \multicolumn{2}{|l|}{ Gender } \\
\hline Female & 6 \\
\hline Male & 34 \\
\hline \multicolumn{2}{|l|}{ Smoking history* } \\
\hline Never-smoker & 4 \\
\hline Smoker & 34 \\
\hline $\mathrm{TT} 1$ & 16 \\
\hline$\geq \mathrm{T} 2$ & 24 \\
\hline \multicolumn{2}{|l|}{$\mathrm{N}$} \\
\hline Negative & 23 \\
\hline Positive & 17 \\
\hline \multicolumn{2}{|l|}{ Pathological stage } \\
\hline I & 20 \\
\hline$\geq \mathrm{II}$ & 20 \\
\hline \multicolumn{2}{|l|}{$\mathrm{pl}^{*}$} \\
\hline Negative & 22 \\
\hline Positive & 15 \\
\hline \multicolumn{2}{|l|}{ ly* } \\
\hline Negative & 28 \\
\hline Positive & 11 \\
\hline \multicolumn{2}{|l|}{$\mathrm{V}^{*}$} \\
\hline Negative & 18 \\
\hline Positive & 21 \\
\hline \multicolumn{2}{|l|}{ Surgical procedure* } \\
\hline$\geq$ Lobectomy & 29 \\
\hline Sublobar resection & 6 \\
\hline \multicolumn{2}{|c|}{ Adjuvant chemotherapy* } \\
\hline None & 13 \\
\hline Administered & 10 \\
\hline \multicolumn{2}{|l|}{ PD-L1 } \\
\hline Negative & 34 \\
\hline Positive & 6 \\
\hline \multicolumn{2}{|l|}{ STAS* } \\
\hline Negative & 5 \\
\hline Positive & 25 \\
\hline
\end{tabular}

*Cases whose data are available. pl: Pleural invasion; ly: lymphatic invasion; v: vascular invasion; PD-L1: programmed death-ligand 1; STAS: spread through air spaces.

Statistical analyses. The associations between EZH2 and patient characteristics were analysed using Fisher's exact test. The overall survival (OS) was defined as the time from the initial surgery until death from any cause, while the recurrence-free survival (RFS) was defined as the time from the initial surgery until recurrence. The Kaplan-Meier method was used to estimate the survival probabilities, and the curves of the two or three groups were statistically compared using the log-rank test. All of the statistical analyses were conducted using the JMP version 12 software program (SAS Institute, Cary, NC, USA). $p$-Values of $<0.05$ were considered to indicate statistically significant differences. 


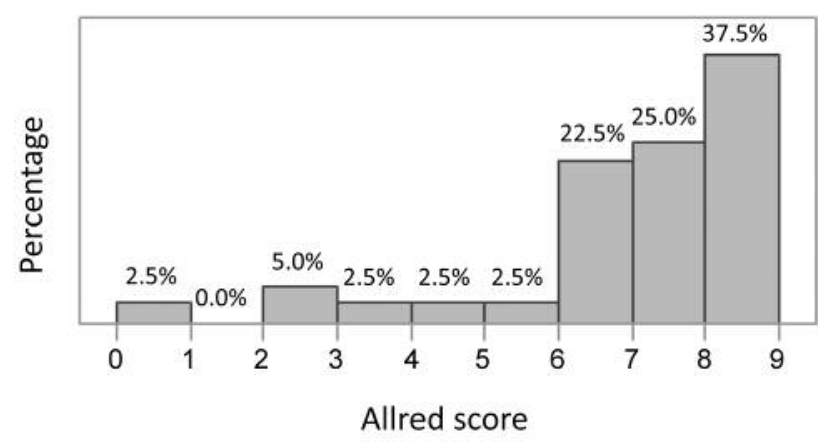

Figure 1. Histogram showing the Allred scores of enhancer of zeste homolog 2 in 40 patients with resected small cell lung cancer.

\section{Results}

Clinicopathological characteristics of patients. Table I shows the characteristics of the patients included in this translational study. The number of patients $<70$ and $\geq 70$ was $21(52.5 \%)$ and $19(47.5 \%)$, respectively. The number of female and male patients was six (15\%) and $34(85 \%)$, respectively. Thirty-four patients $(85 \%)$ had a history of smoking. Sixteen $(40 \%)$ and $24(60 \%)$ patients had T1 and $\geq \mathrm{T} 2$ tumor, respectively, and 17 (43\%) patients were positive for lymph node metastasis. Twenty (50\%) and $20(50 \%)$ patients were diagnosed with pathological stage I and II or III, respectively. Pathological examinations revealed pl, ly, and $\mathrm{v}$ in $15(41 \%), 11(28 \%)$, and $21(54 \%)$ patients, respectively. Twenty-nine ( $83 \%)$ patients underwent surgical resection of more than one lobe, while six $(17 \%)$ received sublobar resection. Ten (43\%) patients received adjuvant chemotherapy. PD-L1 and STAS were positive in six (15\%) and twenty-five (83\%) patients, respectively.

Prevalence of EZH2 expression and its association with the clinicopathological characteristics. Among 40 patients, one $(2.5 \%)$, zero $(0 \%)$, two $(5 \%)$, one $(2.5 \%)$, one $(2.5 \%)$, one $(2.5 \%)$, nine $(22.5 \%), 10(25.0 \%)$ and $15(37.5 \%)$ showed Allred score of 0, 1, 2, 3, 4, 5, 6, 7 and 8, respectively (Figure 1). Mean Allred score for EZH2 was 6.5 and therefore, cutoff value was set as Allred score of 7. Therefore, EZH2 positivity and negativity were found in $25(62.5 \%)$ and 15 $(37.5 \%)$ patients, respectively. According to the Fisher's exact test, positivity for EZH2 was not significantly associated with any clinicopathological features (Table II).

Survival analyses according to the EZH2 expression. RFS and OS after surgical resection were not significantly different between EZH2-negative and EZH2-high patients ( $p=0.68$ and $p=0.80$, respectively; Figure $2 \mathrm{~A}$ and $2 \mathrm{~B})$. The five-year RFS in EZH2-negative and EZH2-positive patients
Table II. Association between EZH2 and the clinicopathological factors in patients with resected small cell lung cancer.

\begin{tabular}{|c|c|c|c|}
\hline Factors & $\mathrm{n}$ & $\begin{array}{c}\text { EZH2 } \\
\text { Negative/Positive }\end{array}$ & $p$-Value \\
\hline \multicolumn{4}{|l|}{ Age (years) } \\
\hline$<70$ & 21 & $10 / 11$ & \multirow[t]{2}{*}{0.20} \\
\hline$\geq 70$ & 19 & $5 / 14$ & \\
\hline \multicolumn{4}{|l|}{ Gender } \\
\hline Female & 6 & $2 / 4$ & \multirow[t]{2}{*}{1.00} \\
\hline Male & 34 & $13 / 21$ & \\
\hline \multicolumn{4}{|l|}{ Smoking history* } \\
\hline Never-smoker & 4 & $1 / 3$ & \multirow[t]{2}{*}{1.00} \\
\hline Smoker & 34 & $12 / 22$ & \\
\hline \multicolumn{4}{|l|}{$\mathrm{T}$} \\
\hline $\mathrm{T} 1$ & 16 & $5 / 11$ & \multirow[t]{2}{*}{0.74} \\
\hline$\geq \mathrm{T} 2$ & 24 & $10 / 14$ & \\
\hline \multicolumn{4}{|l|}{$\mathrm{N}$} \\
\hline Negative & 23 & $9 / 14$ & \multirow[t]{2}{*}{1.00} \\
\hline Positive & 17 & $6 / 11$ & \\
\hline \multicolumn{4}{|l|}{ Pathological stage } \\
\hline I & 20 & $8 / 12$ & \multirow[t]{2}{*}{1.00} \\
\hline$\geq \mathrm{II}$ & 20 & $7 / 13$ & \\
\hline \multicolumn{4}{|l|}{$\mathrm{pl}^{*}$} \\
\hline Negative & 22 & $9 / 13$ & \multirow[t]{2}{*}{0.74} \\
\hline Positive & 15 & $5 / 10$ & \\
\hline \multicolumn{4}{|l|}{$1 y^{*}$} \\
\hline Negative & 28 & $12 / 16$ & \multirow[t]{2}{*}{0.48} \\
\hline Positive & 11 & $3 / 8$ & \\
\hline \multicolumn{4}{|l|}{$\mathrm{v}^{*}$} \\
\hline Negative & 18 & $10 / 8$ & \multirow[t]{2}{*}{0.06} \\
\hline Positive & 21 & $5 / 16$ & \\
\hline \multicolumn{4}{|l|}{ Surgical procedure* } \\
\hline$\geq$ Lobectomy & 29 & $14 / 15$ & \multirow[t]{2}{*}{0.06} \\
\hline Sublobar resection & 6 & $0 / 6$ & \\
\hline \multicolumn{4}{|c|}{ Adjuvant chemotherapy* } \\
\hline None & 13 & $1 / 12$ & \multirow[t]{2}{*}{0.28} \\
\hline Administered & 10 & $3 / 7$ & \\
\hline \multicolumn{4}{|l|}{ PD-L1 } \\
\hline Negative & 34 & $14 / 20$ & \multirow[t]{2}{*}{0.38} \\
\hline Positive & 6 & $1 / 5$ & \\
\hline \multicolumn{4}{|l|}{ STAS* } \\
\hline Negative & 5 & $1 / 4$ & \multirow[t]{2}{*}{1.00} \\
\hline Positive & 25 & $8 / 17$ & \\
\hline
\end{tabular}

*Cases whose data are available. EZH2: Enhancer of zeste homolog 2; pl: pleural invasion; ly: lymphatic invasion; v: vascular invasion; PDL1: programmed death-ligand 1; STAS: spread through air spaces.

were $32.0 \%$ and $23.8 \%$, respectively. The five-year OS in EZH2-negative and EZH2-positive patients were $48.1 \%$ and $50.6 \%$, respectively.

\section{Discussion}

In the current study, EZH2 positivity was identified in 25 $(62.5 \%)$ among 40 patients with SCLC. As we reported previously, the frequency of EZH2 expression in the resected lung adenocarcinoma was $34.5 \%$, which was lower than that 
A

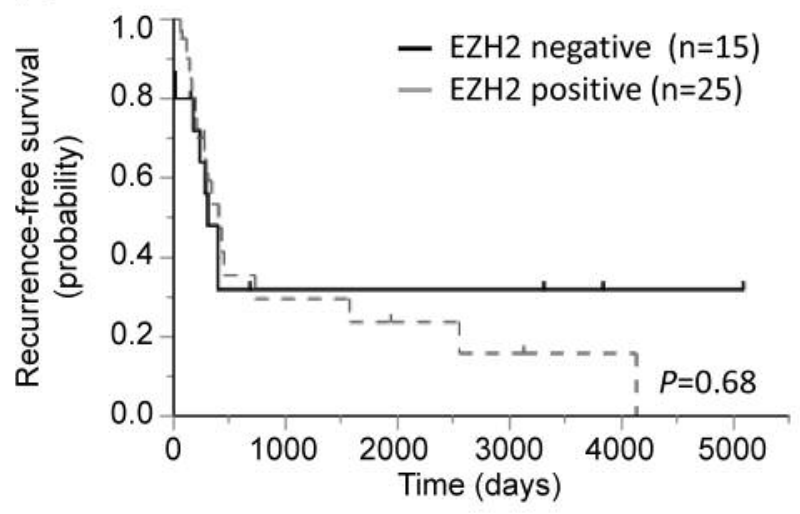

B

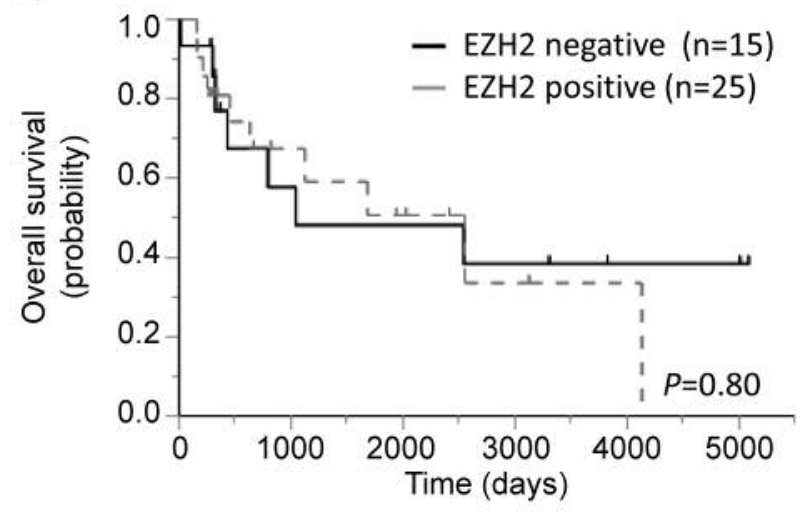

Figure 2. The (A) recurrence-free and (B) overall survival according to enhancer of zeste homolog 2 expression in 40 patients with resected small cell lung cancer.

in the resected SCLC (16). In contrast, the frequency of EZH2 expression in the resected squamous cell carcinoma was as high as $88.9 \%$ (16). However, when setting the cutoff of EZH2 expression at 3 (16), EZH2 positivity was found in $37(92.5 \%)$ among 40 SCLC patients. These discrepant frequencies suggested that EZH2 expression might vary between the different histological types. Furthermore, although the EZH2 expression was significantly associated with the clinicopathologically invasive features in lung adenocarcinoma (16), the present study demonstrated no significant associations between EZH2 positivity and clinicopathological features. Furthermore, RFS and OS were not significantly different between EZH2-negative and EZH2-positive patients, while the presence of EZH2 was reported to negatively affect postoperative survivals in lung adenocarcinoma $(8,16)$. Several reasons can be considered for these discrepancies: the difference of EZH2 roles in each histological type and the limited sample size of the present.

High expression of EZH2 in patients with SCLC suggested that such patients might be targetable by EZH2 inhibitors. In non-Hodgkin lymphoma, an EZH2 inhibitor, EPZ6438, is under investigation by a phase I/II study (22). Although EZH2 has not yet been examined for its clinical targetability by EZH2 inhibitors, preclinical data showed that growth of SCLC could be suppressed by the knockdown of EZH2 (23). Furthermore, a report by Gardner et al. demonstrated that EZH2 drived acquired resistance to chemotherapeutic agents in SCLC and combination of an EZH2 inhibitor, EPZ011989, with standard cytotoxic chemotherapy suppressed the emergence of acquired resistance (24). Recently, EZH2 was reported to control the mechanisms of adaptive resistance to tumor immunotherapy in human skin cutaneous melanoma (25). The inactivation of EZH2 reversed resistance to CTLA4 or Interleukin-2 (IL-2) immunotherapy and synergized with
anti-CTLA-4 and IL-2 immunotherapy, resulting in the suppression of melanoma proliferation. Thus, EZH2 has attracted much attention in the treatment of lung cancer, including both non-small cell lung cancer and SCLC and the above-mentioned preclinical evidence should be clinically investigated in the future studies.

The current study is associated with several limitations, including that it examined a small cohort of patients with resected SCLC. In addition to the further analysis in a larger cohort of patients with resected SCLC, future studies are warranted to elucidate the significance of EZH2 expression in patients with advanced SCLC.

In conclusion, the present study revealed that EZH2 was frequently observed in the resected SCLC and no impacts on postoperative survivals were identified.

\section{Conflicts of Interest}

All the Authors declare no conflicts of interest in association with this study.

\section{Acknowledgements}

The Authors would like to thank Brian T. Quinn for his critical comments on the manuscript.

\section{References}

1 Pignon JP, Arriagada R, Ihde DC, Johnson DH, Perry MC, Souhami RL, Brodin O, Joss RA, Kies MS, Lebeau B, Onoshi $\mathrm{T}$, Østerlind K, Tattersall MHN and Wagner H: A meta-analysis of thoracic radiotherapy for small-cell lung cancer. N Engl J Med 327: 1618-1624, 1992.

2 Weksler B, Nason KS, Shende M, Landreneau RJ and Pennathur A: Surgical resection should be considered for stage I and II small cell carcinoma of the lung. Ann Thorac Surg 94: 889-893, 2012. 
3 Combs SE, Hancock JG, Boffa DJ, Decker RH, Detterbeck FC and Kim AW: Bolstering the case for lobectomy in stages I, II, and IIIA small-cell lung cancer using the National Cancer Data Base. J Thorac Oncol 10: 316-323, 2015.

4 Takenaka T, Takenoyama M, Inamasu E, Yoshida T, Toyokawa G, Nosaki K, Hirai F, Yamaguchi M, Shimokawa M, Seto T and Ichinose Y: Role of surgical resection for patients with limited disease-small cell lung cancer. Lung Cancer 88: 52-56, 2015.

5 Kawano D, Okamoto T, Fujishita T, Suzuki Y, Kitahara H, Shimamatsu S and Maehara Y: Surgical results of resectable small cell lung cancer. Thorac Cancer 6: 141-145, 2015.

6 Antonia SJ, Lopez-Martin JA, Bendell J, Ott PA, Taylor M, Eder JP, Jager D, Pietanza MC, Le DT, de Braud F, Morse MA, Ascierto PA, Horn L, Amin A, Pillai RN, Evans J, Chau I, Bono P, Atmaca A, Sharma P, Harbison CT, Lin CS, Christensen O and Calvo E: Nivolumab alone and nivolumab plus ipilimumab in recurrent small-cell lung cancer (CheckMate 032): a multicentre, open-label, phase 1/2 trial. Lancet Oncol 17: 883-895, 2016.

7 Hamamoto $\mathrm{R}$ and Nakamura Y: Dysregulation of protein methyltransferases in human cancer: An emerging target class for anticancer therapy. Cancer Sci 107: 377-384, 2016.

8 Takawa M, Masuda K, Kunizaki M, Daigo Y, Takagi K, Iwai Y, Cho HS, Toyokawa G, Yamane Y, Maejima K, Field HI, Kobayashi T, Akasu T, Sugiyama M, Tsuchiya E, Atomi Y, Ponder BA, Nakamura $\mathrm{Y}$ and Hamamoto R: Validation of the histone methyltransferase EZH2 as a therapeutic target for various types of human cancer and as a prognostic marker. Cancer Sci 102: 1298-1305, 2011.

9 Bachmann IM, Halvorsen OJ, Collett K, Stefansson IM, Straume O, Haukaas SA, Salvesen HB, Otte AP and Akslen LA: EZH2 expression is associated with high proliferation rate and aggressive tumor subgroups in cutaneous melanoma and cancers of the endometrium, prostate, and breast. J Clin Oncol 24: 268-273, 2006.

10 Zhang H, Qi J, Reyes JM, Li L, Rao PK, Li F, Lin CY, Perry JA, Lawlor MA, Federation A, De Raedt T, Li YY, Liu Y, Duarte MA, Zhang Y, Herter-Sprie GS, Kikuchi E, Carretero J, Perou CM, Reibel JB, Paulk J, Bronson RT, Watanabe H, Brainson CF, Kim CF, Hammerman PS, Brown M, Cichowski K, Long H, Bradner JE and Wong KK: Oncogenic deregulation of EZH2 as an opportunity for targeted therapy in lung cancer. Cancer Discov 6: 1006-1021, 2016.

11 Behrens C, Solis LM, Lin H, Yuan P, Tang X, Kadara H, Riquelme E, Galindo H, Moran CA, Kalhor N, Swisher SG, Simon GR, Stewart DJ, Lee JJ and Wistuba II: EZH2 protein expression associates with the early pathogenesis, tumor progression, and prognosis of non-small cell lung carcinoma. Clin Cancer Res 19: 6556-6565, 2013.

12 McCabe MT, Ott HM, Ganji G, Korenchuk S, Thompson C, Van Aller GS, Liu Y, Graves AP, Della Pietra A, 3rd, Diaz E, LaFrance LV, Mellinger M, Duquenne C, Tian X, Kruger RG, McHugh CF, Brandt M, Miller WH, Dhanak D, Verma SK, Tummino PJ and Creasy CL: EZH2 inhibition as a therapeutic strategy for lymphoma with EZH2-activating mutations. Nature 492: 108-112, 2012.

13 Toyokawa G, Takenoyama M and Ichinose Y: Do mutations of the enhancer of zeste homolog 2 gene exist in small-cell lung cancer? J Thorac Oncol 8: e103, 2013.

14 Hubaux R, Thu KL, Coe BP, MacAulay C, Lam S and Lam WL: EZH2 Promotes E2F-driven SCLC tumorigenesis through modulation of apoptosis and cell-cycle regulation. J Thorac Oncol 8: 1102-1106, 2013.
15 Takada K, Okamoto T, Shoji F, Shimokawa M, Akamine T, Takamori S, Katsura M, Suzuki Y, Fujishita T, Toyokawa G, Morodomi Y, Okano S, Oda Y and Maehara Y: Clinical significance of PD-L1 protein expression in surgically resected primary lung adenocarcinoma. J Thorac Oncol 11: 1879-1890, 2016.

16 Toyokawa G, Takada K, Okamoto T, Kozuma Y, Matsubara T, Haratake N, Akamine T, Takamori S, Katsura M, Shoji F, Hamamoto R, Oda Y and Maehara Y: Elevated metabolic activity on (18)F-FDG PET/CT is associated with the expression of EZH2 in non-small cell lung cancer. Anticancer Res 37: 1393$1401,2017$.

17 Allred DC, Harvey JM, Berardo M and Clark GM: Prognostic and predictive factors in breast cancer by immunohistochemical analysis. Mod Pathol 11: 155-168, 1998.

18 Herbst RS, Soria JC, Kowanetz M, Fine GD, Hamid O, Gordon MS, Sosman JA, McDermott DF, Powderly JD, Gettinger SN, Kohrt HE, Horn L, Lawrence DP, Rost S, Leabman M, Xiao Y, Mokatrin A, Koeppen H, Hegde PS, Mellman I, Chen DS and Hodi FS: Predictive correlates of response to the anti-PD-L1 antibody MPDL3280A in cancer patients. Nature 515: 563-567, 2014.

19 Shiono S and Yanagawa N: Spread through air spaces is a predictive factor of recurrence and a prognostic factor in stage I lung adenocarcinoma. Interact Cardiovasc Thorac Surg 23: 567$572,2016$.

20 Warth A, Muley T, Kossakowski CA, Goeppert B, Schirmacher P, Dienemann H and Weichert W: Prognostic impact of intraalveolar tumor spread in pulmonary adenocarcinoma. Am J Surg Pathol 39: 793-801, 2015

21 Toyokawa G, Yamada Y, Tagawa T, Kinoshita F, Kozuma Y, Matsubara T, Haratake N, Takamori S, Akamine T, Hirai F, Oda $\mathrm{Y}$ and Maehara Y: High frequency of spread through air spaces in resected small cell lung cancer. Anticancer Res 38: 1821$1825,2017$.

22 Hamamoto R, Saloura V and Nakamura Y: Critical roles of nonhistone protein lysine methylation in human tumorigenesis. Nat Rev Cancer 15: 110-124, 2015.

23 Byers LA, Wang J, Nilsson MB, Fujimoto J, Saintigny P, Yordy J, Giri U, Peyton M, Fan YH, Diao L, Masrorpour F, Shen L, Liu W, Duchemann B, Tumula P, Bhardwaj V, Welsh J, Weber S, Glisson BS, Kalhor N, Wistuba II, Girard L, Lippman SM, Mills GB, Coombes KR, Weinstein JN, Minna JD and Heymach JV: Proteomic profiling identifies dysregulated pathways in small cell lung cancer and novel therapeutic targets including PARP1. Cancer Discov 2: 798-811, 2012.

24 Gardner EE, Lok BH, Schneeberger VE, Desmeules P, Miles LA, Arnold PK, Ni A, Khodos I, de Stanchina E, Nguyen T, Sage J, Campbell JE, Ribich S, Rekhtman N, Dowlati A, Massion PP, Rudin CM and Poirier JT: Chemosensitive relapse in small cell lung cancer proceeds through an EZH2-SLFN11 Axis. Cancer Cell 31: 286-299, 2017.

25 Zingg D, Arenas-Ramirez N, Sahin D, Rosalia RA, Antunes AT, Haeusel J, Sommer L and Boyman O: The histone methyltransferase Ezh2 controls mechanisms of adaptive resistance to tumor immunotherapy. Cell Rep 20: 854-867, 2017.

Received March 20, 2018

Revised April 17, 2018

Accepted April 18, 2018 